\title{
GRANULOMETRIA DE PRAIAS DO MUNICÍPIO DE UBATUBA, SP*
}

\author{
ARARY MARCONI ** \\ IBRAHIM OCTAVIO ABRAHĀO**
}

\begin{abstract}
RESUMO
Os parâmetros propostos por Folk e Ward (SUGUIO, 1973), diâmetro médio $(\mathrm{Mz})$, desvio padrão gráfico inclusivo $\left(\sigma_{\mathrm{I}}\right)$, assimetria gráfica inclusiva $\left(\mathrm{Sk}_{\mathrm{I}}\right)$ e curtose gráfica $\left(\mathrm{K}_{\mathrm{G}}\right)$, são utilizados na caracterização granulométrica de 15 praias do litoral de Ubatuba, SP. Os resultados obtidos mostram que, em geral, essas praias são de granulação fina, com material bem selecionado. As curvas de distribuição de classes de frequiência têm, geralmente, assimetria negativa e são meso ou leptocúrticas.
\end{abstract}

\section{INTRODUÇÃO}

O município de Ubatuba, litoral norte do estado de São Paulo, tem, em seus $80 \mathrm{~km}$ de litoral, cerca de 70 praias, a maior parte das quais é inacessivel ou de acesso muito difícil.

Com a finalidade de examinar caracteres granulométricos das praias dessa região, estudaram-se as areias de 15 praias, procurando abranger a maior parte do litoral do município. Estudaram-se tão somente os parâmetros granulométricos, não se cogitando da composição mineralógica.

\section{REVISÃO DA LITERATURA}

As areias de praias têm sido intensamente estudadas, em sua granulometria, a fim de estabelecer parâmetros que permitam caracterizá-las e diferenciá-las de outros sedimentos arenosos. Segundo DOEGLAS (1946), o tamanho de grârulos de areia é função principalmente do material de origem, tendo efeito secundário a ação de ondas e de correntes marinhas. Em face disso, as areias de praia não teriam uma distribuição de freqüência de tamanho caracteristica. Todavia, FRIEDMAN (1961), estudando grande número de praias da costa leste dos Estados Unidos, conclui que a assimetria (Sk. negativa é característica das curvas de freqüência de tamanho dessas areias. Também MARTINS (1965), em praias do Rio Grande do Sul, encontra assimetria negativa, sendo raras as curvas com assimetria positiva.

FREITAS (1951a, b, 1953), em praias do litoral paulista, verifica que em São Sebastião a areia é grosseira e mal selecionada, em contraste com areias da Praia Grande e do Guarujá, que são finas e melhor selecionadas. A curva de freqüência de tamanho é simétrica em São Sebastião e de assimetria negativa na Praia Grande e no Guarujá.

* Entregue para publicação em 19/12/1975.

* Departamento de Solos e Geologia, ESALQ - USP. 


\section{MATERIAL E MÉTODO}

Foram estudadas amostras de 15 praias do litoral de Ubatuba, SP, abrangendo uma extensão de cerca de $50 \mathrm{~km}$ de litoral. As amostras foram retiradas na linha d'água das praias, a meia maré, até a profundidade de $20 \mathrm{~cm}$. A fig. 1 mostra a localização das prajas estudadas.

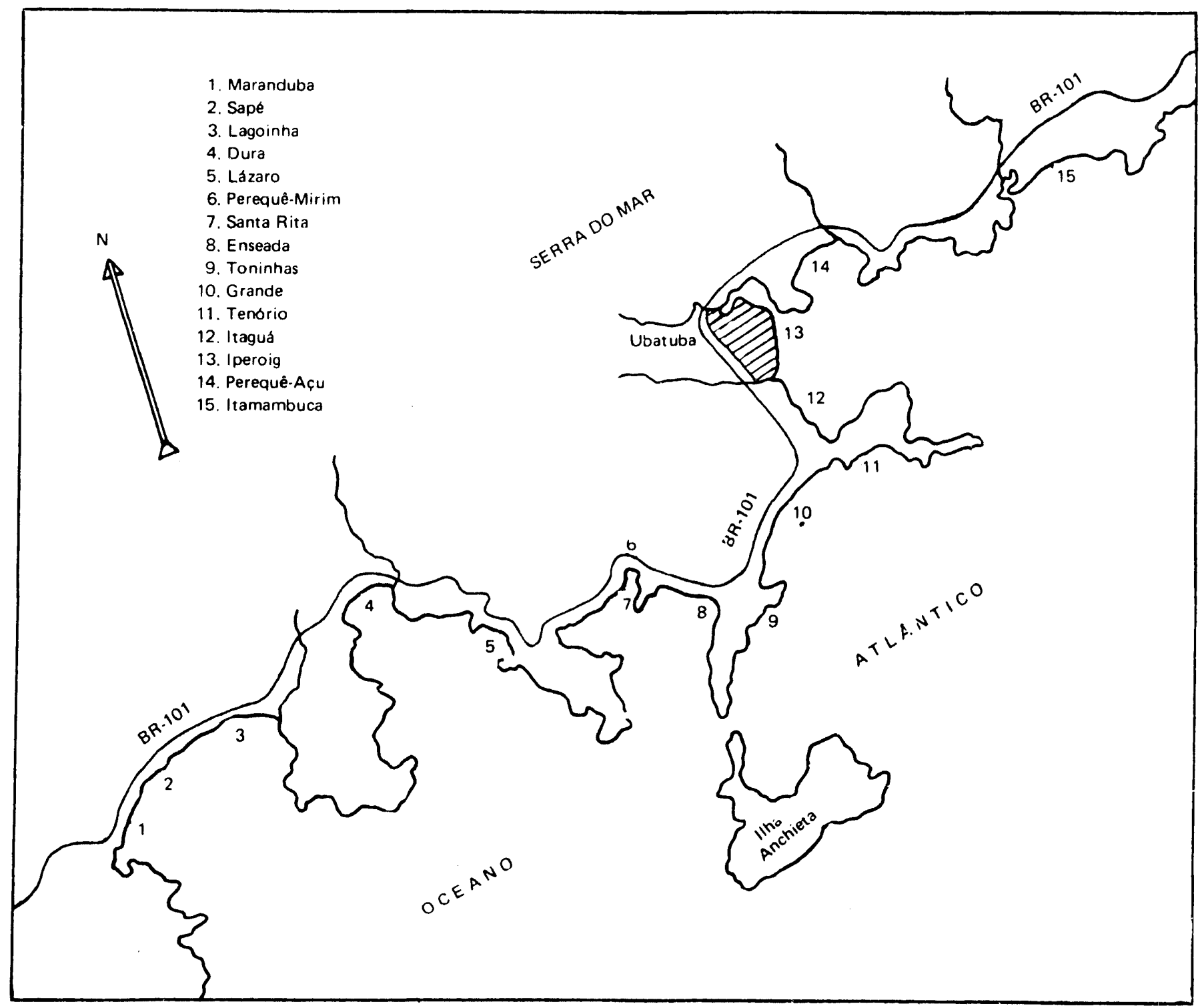

Figura 1 - Litoral de Ubatuba, SP. Localização das praias estudadas.

Após secagem em estufa a $60-70^{\circ} \mathrm{C}$, a amostra foi homogeneizada e $50 \mathrm{~g}$ do material foram passados em peneiras, de modo convencional. Utilizou-se jogo de peneiras de malhas com intervalo de $1 \phi$. Os valores obtidos, acumulados, foram lançados em papel de probabilidade aritmética, utilizando-se escala $\phi$ (fig. 2).

Os parâmetros estatísticos utilizados foram os propostos por Folk e Ward (SUGUIO, 1973): diâmetro médio $(\mathrm{Mz})$, desvio padrão gráfico inclusivo $\left(\sigma_{\mathrm{J}}\right)$, assimetria gráfica inclusiva $\left(\mathrm{Sk}_{\mathrm{I}}\right)$ e curtose gráfica $\left(\mathrm{K}_{\mathrm{G}}\right)$. Os valores necessários ao cálculo desses parâmetros foram extraídos das curvas de freqüência acumulada (fig. 2). 


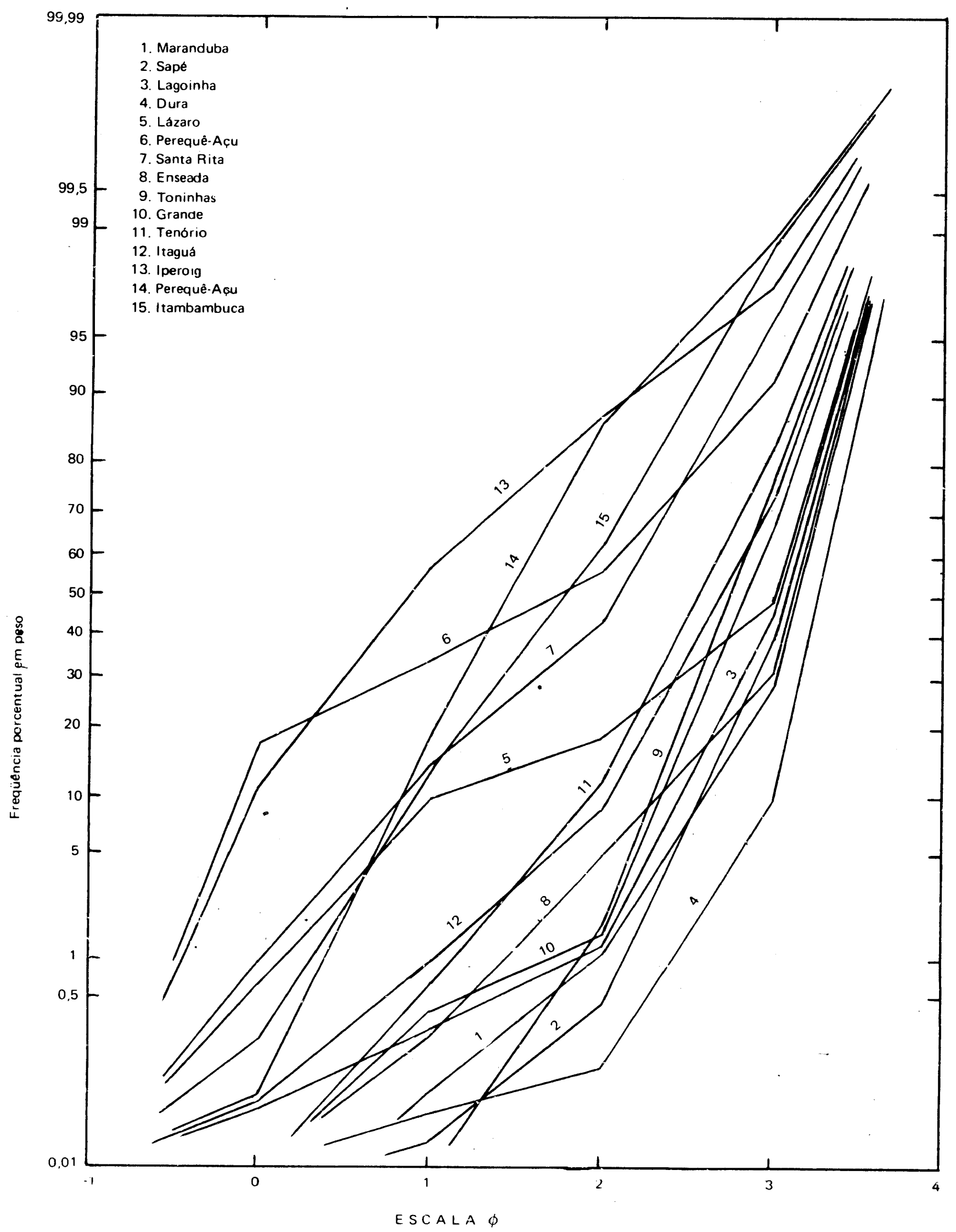

Figura 2 - Curvas acumulativas de distribuição granulométrica de praias de Ubatuba, SP. 
RESULTADOS

Quadro I - Granulometria de praias de Ubatuba, SP.

\begin{tabular}{lrrrrr}
\hline Praias & \multicolumn{5}{c}{ Tamanho $(\mathrm{mm})$} \\
\cline { 2 - 6 } & $2,0 \mathrm{a} 1,0$ & $1,0 \mathrm{a} 0,5$ & $0,5 \mathrm{a} 0,25$ & 0,25 a 0,125 & 0,125 a 0,062 \\
\hline Maranduba & 0,00 & 0,07 & 1,10 & 27,37 & 71,47 \\
Sapé & 0,00 & 0,02 & 0,41 & 39,43 & 60,14 \\
Lagoinha & 0,05 & 0,22 & 0,96 & 44,40 & 54,37 \\
Dura & 0,00 & 0.04 & 0,08 & 9,96 & 89,93 \\
Lázaro & 0,62 & 9,15 & 8,25 & 30,46 & 51,52 \\
Perequê-Mirim & 16,98 & 16,63 & 22,45 & 35.35 & 8,59 \\
Santa Rita & 0,97 & 13,04 & 29,72 & 52,40 & 3,87 \\
Enseada & 0,00 & 0,21 & 4,67 & 26,23 & 68,89 \\
Toninhas & 0,00 & 0,01 & 1,75 & 75,79 & 22,45 \\
Grande & 0,00 & 0,37 & 1,18 & 65,30 & 33.15 \\
Tenório & 0,01 & 0,61 & 11,19 & 71,37 & 16.81 \\
Itaguá & 0,05 & 0,89 & 7,93 & 64,97 & 26,16 \\
Iperoig & 11,11 & 45,49 & 30,99 & 10,08 & 2,33 \\
Perequê-Açu & 0,06 & 18,49 & 68,22 & 12,18 & 1,05 \\
Itamambuca & 0,21 & 13,34 & 49,26 & 36,01 & 1,17 \\
\hline
\end{tabular}

Quadro II - Valores de parâmetros estat ísticos, calculados segundo Folk e Ward (SUGUIO, 1973), utilizando escala $\phi$, para praias de Ubatuba, SP.

\begin{tabular}{llllll}
\hline Praias & $\mathrm{Mz}$ & $\tau_{\mathrm{I}}$ & $\mathrm{Sk}_{\mathrm{n}}$ & $\mathrm{K}_{\mathrm{G}}$ \\
\hline Maranduba & 3,08 & 0.33 & -0.28 & 1.35 \\
Sapé & 3,03 & 0.32 & -0.23 & 1,06 \\
Lagoinha & 2,98 & 0,36 & -0.25 & 1.01 \\
Dura & 3,26 & 0,25 & $-0,15$ & 1,45 \\
Lázaro & 2,68 & 0,80 & $-0,66$ & 1,21 \\
Perequê-Mirim & 1,46 & 1,18 & $-0,22$ & 0,72 \\
Santa Rita & 1,92 & 0,74 & $-0,31$ & 0,98 \\
Enseada & 3,01 & 0,44 & $-0,42$ & 1,37 \\
Toninhas & 2,74 & 0,35 & 0,00 & 1,03 \\
Grande & 2,82 & 0,36 & $-0,05$ & 0,95 \\
Tenório & 2,56 & 0,48 & $-0,05$ & 1,07 \\
Itaguá & 2,66 & 0,49 & $-0,13$ & 1,01 \\
Iperoig & 0,95 & 0,84 & 0,21 & 1,06 \\
Perequê-Açu & 1,44 & 0,51 & 0.08 & 1,05 \\
Itamambuca & 1,73 & 0,62 & $-0,08$ & 0,92 \\
\hline
\end{tabular}




\section{DISCUSSÃo}

\section{Diâmetro médio (Mz):}

$\mathrm{O}$ diâmetro médio reflete a média geral do tamanho dos grânulos do sedimento.

As praias estudadas são de granulação fina, tendo o diâmetro médio situado na areia fina ou muito fina. Apenas a praia de Iperoig mostra textura grosseira e as de Perequê-Mirim, Santa Rita, Perequê-Açu e Itamambuca mostram textura média, ainda que as duas primeiras tenham a moda na areia fina.

Esses resultados confirmam os encontrados por FREITAS (1951a, b, 1953) para o Guarujá e para a Praia Grande, também praias de areia fina. Perequê-Mirim, Santa Rita, Perequê-Açu e Itamambuca assemelham-se mais a São Sebastião, praia de granulação mais grosseira.

\section{Desvio padrão médio inclusivo $(\sigma /)$}

Esse parâmetro permite verificar o grau de seleção granulométrica do material constituinte do sedimento. Para uma seleção perfeita, tem-se $\sigma_{I}=0$.

Granulometricamente, o material é bem selecionado para um grande número de praias. Lázaro, Santa Rita, Iperoig e Itamambuca mostram-se moderadamente selecionadas e apenas a praia do Perequê-Mirim é pobremente selecionada, mostrando pequenas diferenças entre as classes de freqüência. A praia Dura é a de melhor selecionamento, com praticamente $90 \%$ dos grânulos situados na mesma classe de tamanho.

Deve ser observado que o selecionamento é melhor para as praias de menor diâmetro médio, portanto para os sedimentos mais finos. Os histogramas das fig. 3 a 17 permitem verificar que as praias de granulação mais grosseira, Perequê-Mirim, Lázaro, Santa Rita e Iperoig, são as de menor selecionamento e aquelas que mostram maior número de classes de freqüência.

\section{Assimetria gráfica inclusiva $\left(\mathbf{S k}_{\mathbf{l}}\right)$}

Permite estudar a assimetria da curva de distribuição de classes de freqüência. Para uma curva normal, tem-se $\mathrm{SkI}_{\mathrm{I}}=0$, enquanto que valores negativos ou positivos indicam deslocamento do pico para o lado dos sedimentos mais finos ou mais grossos, respectivamente.

Confirmando conclusões de FRIEDMAN-(1961) e de MARTINS (1965), as praias do litoral de Ubatuba mostram assimetria negativa, chegando ao extremo na praia do Lázaro $\left(\mathrm{SkI}_{\mathrm{I}}=-0,66\right)$, com assimetria muito negativa. Apenas a praia de Iperoig mostra assimetria positiva, enquanto a do Perequê-Açu, embora com pequena assimetria positiva, pode ser enquadrada como tendo a curva de distribuição simétrica.

É interessante observar que a assimetria negativa é mais acentuada nas oito primeiras praias, isto é, na região compreendida entre a Maranduba e a Enseada. 


\section{Curtose gráfica $\left(K_{G}\right)$}

Mostra a relação de seleção entre as extremidades e a parte central da curva. Seu valor para a curva normal é igual a 1,00.

Apenas a praia do Perequê-Mirim apresenta curva platicúrtica, com achatamento acentuado. As demais são meso ou leptocúrticas, com valores de $\mathrm{K}_{\mathrm{G}}$ em torno de 1,00 para as mesocúrticas e superiores a 1,20 para as leptocúrticas. A praia Dura, com $\mathrm{K}_{\mathrm{G}} \triangleq 1,45$ é a que apresenta pico mais agudo.

A fig. 18 permite comparar os parâmetros estudados para as 15 praias.

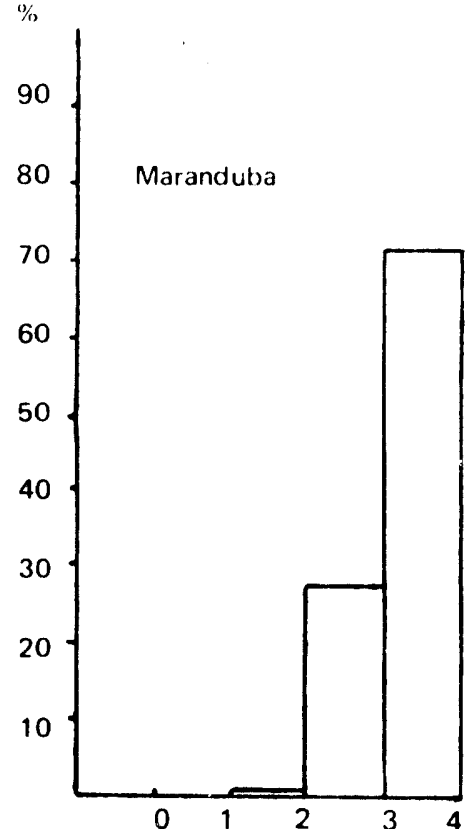

Figura 3 - Histograma de distribuição granulométrica

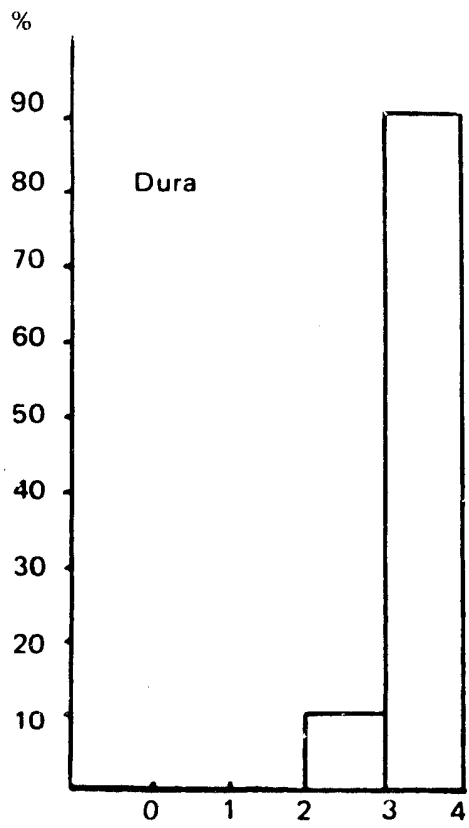

Figura 6 - Histograma de distribuição granulométrica

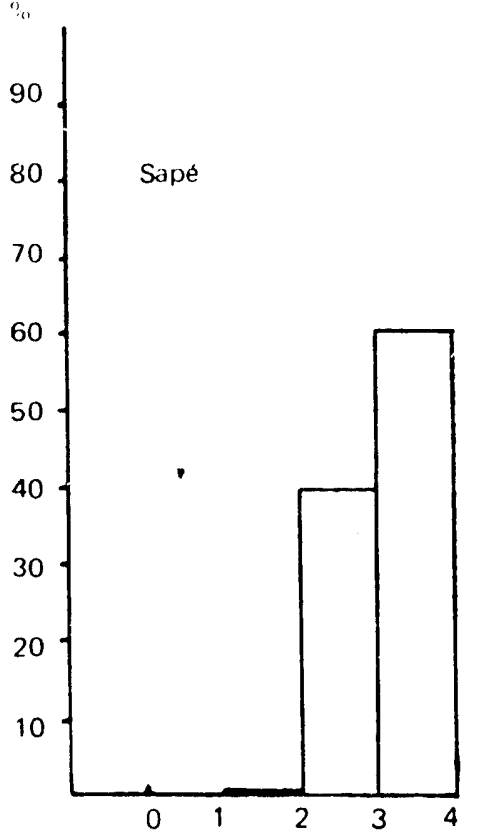

Figura 4 - Histograma de distribuição granulometrica

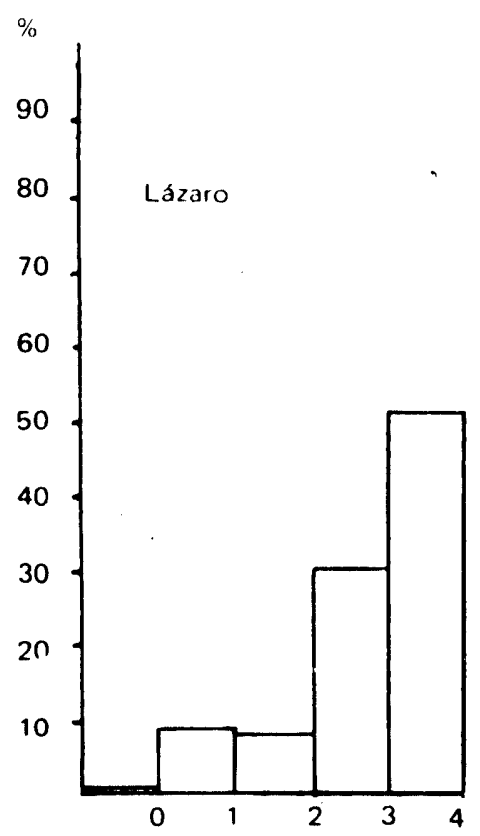

Figura 7.- Histograma de distribuição granulométrica

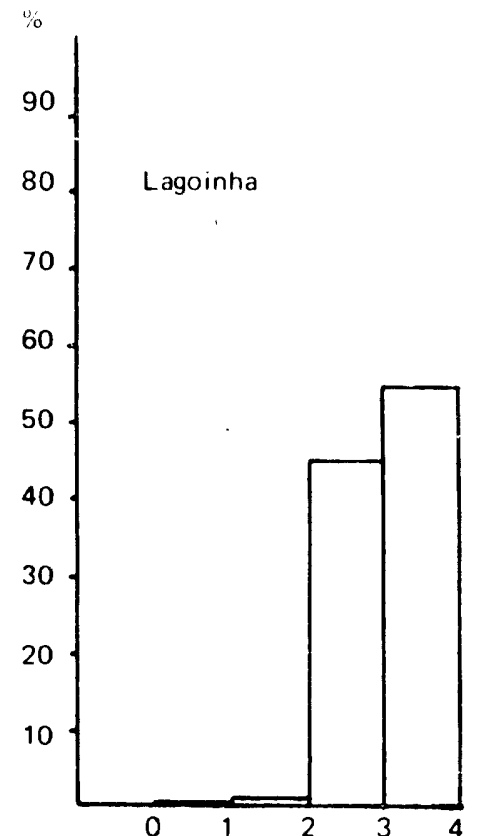

Figura 5 - Histograma de distribuição granulométrica

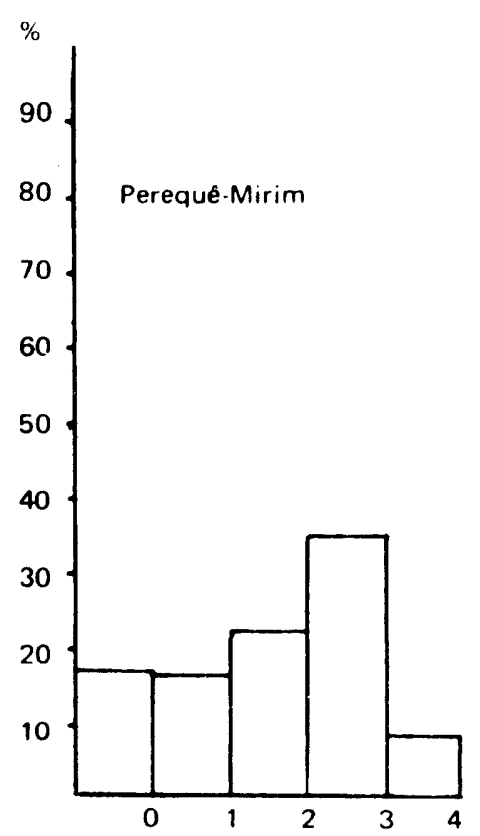

Figura 8 - Histograma de distribuição granulométrica 

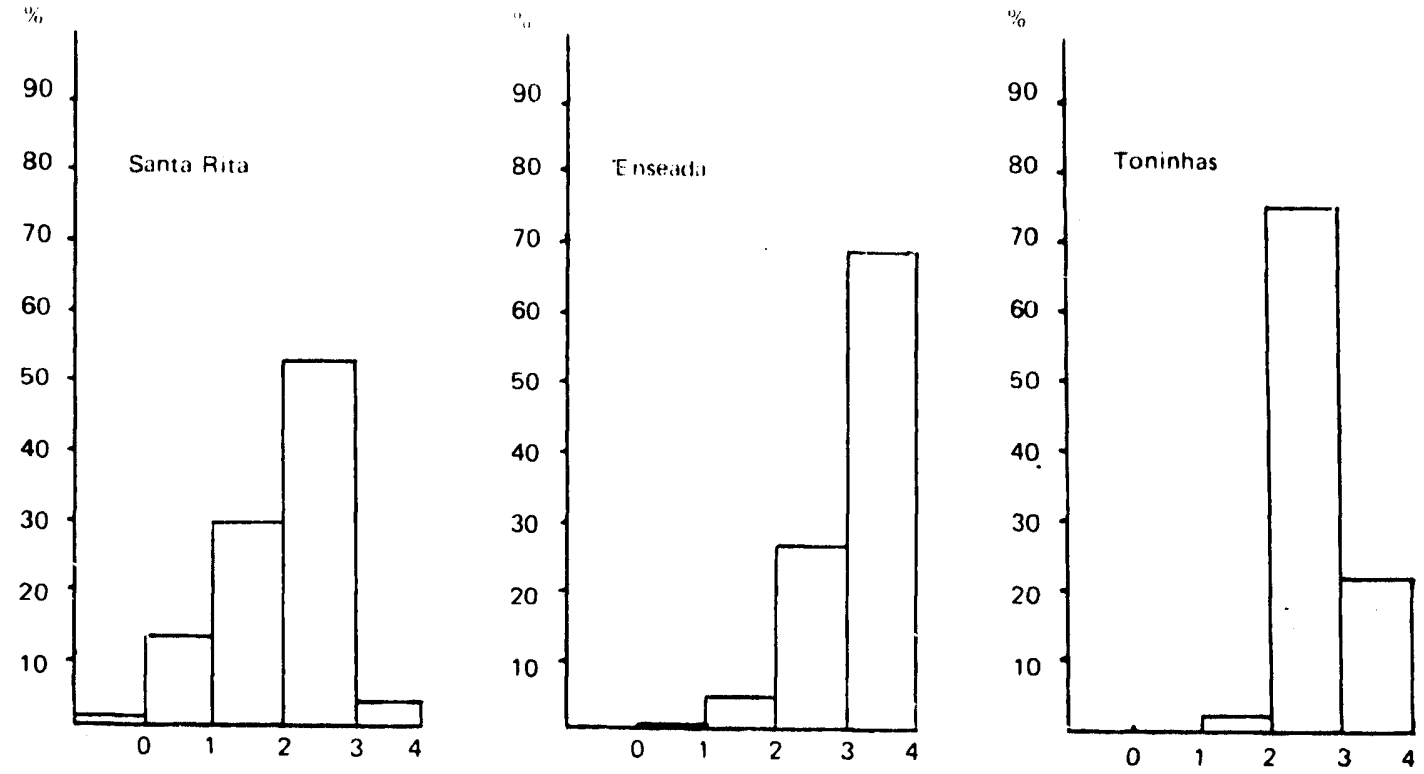

Figura 9 - Histograma de

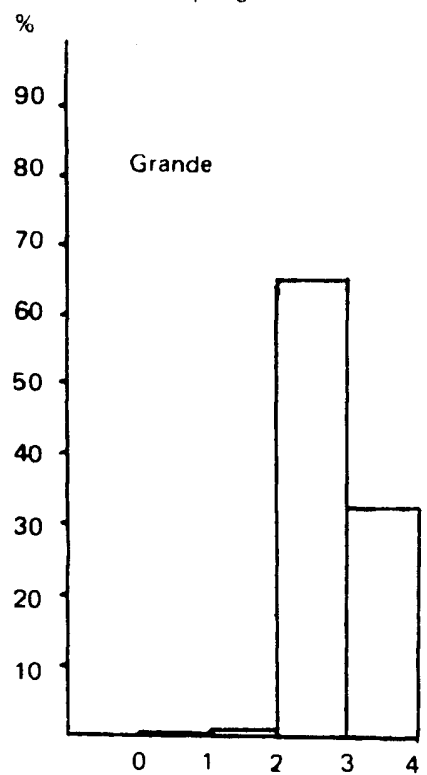

Figura 10 - Histograma de

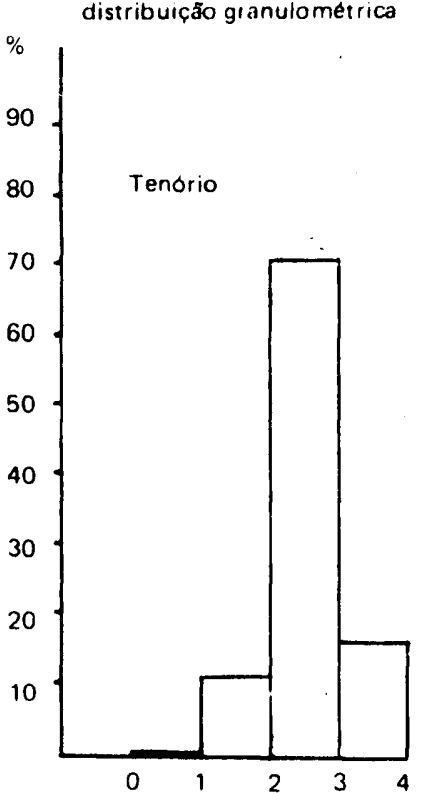

Figura 11 - Histograma de

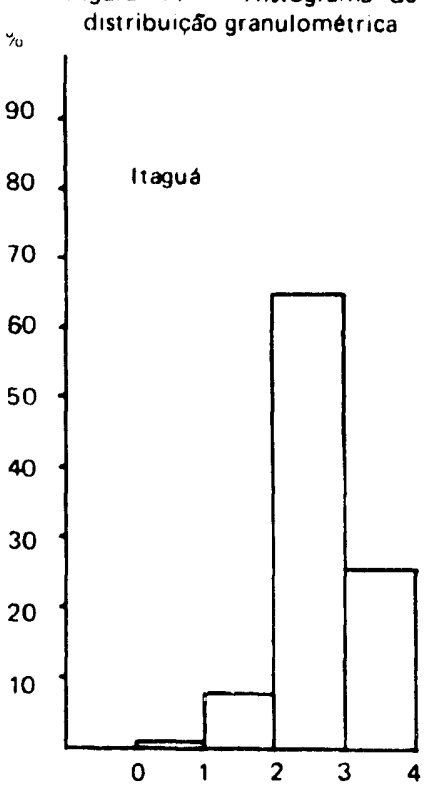

Figura 12 - Histograma de

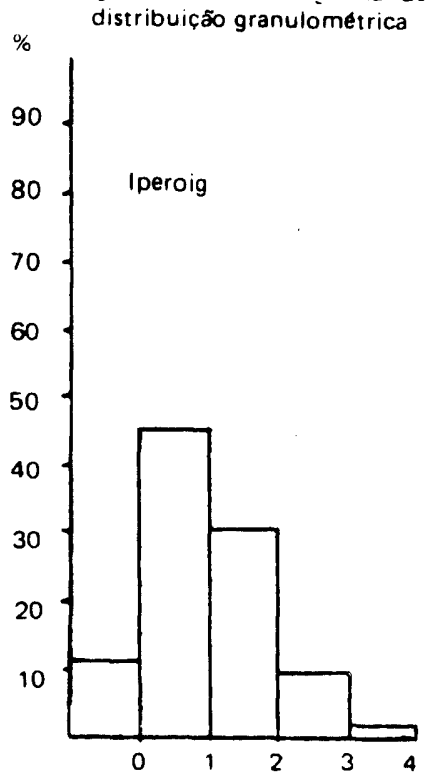

Figura 13 - Mistograma de

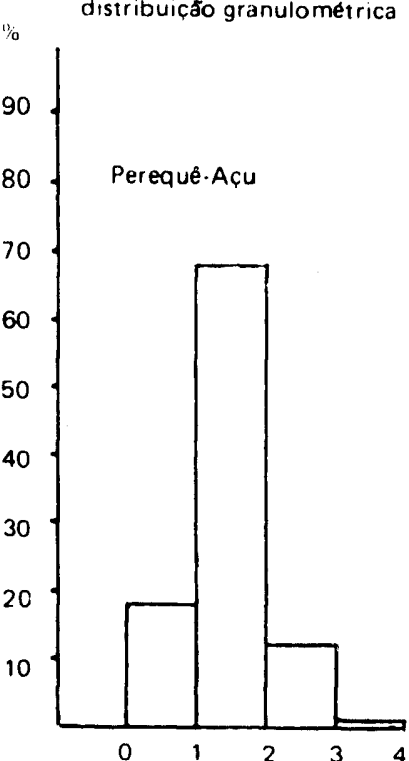

Figura 14 - Histograma de

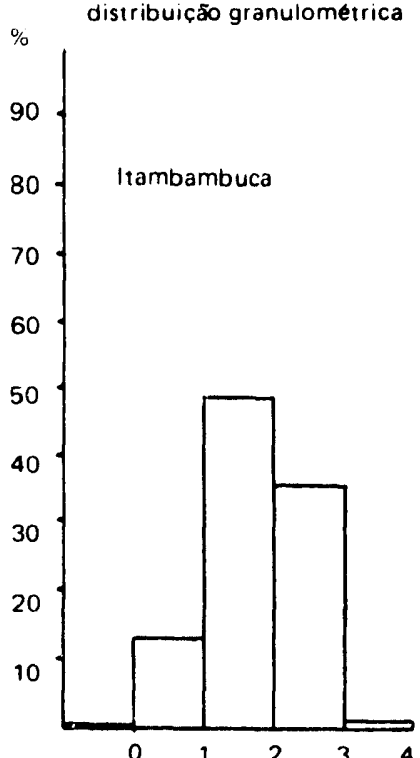

Figura 15 - Histograma de distribuição granulometrica

Figura 16 - Histograma de distribuiçáo granulometrica 


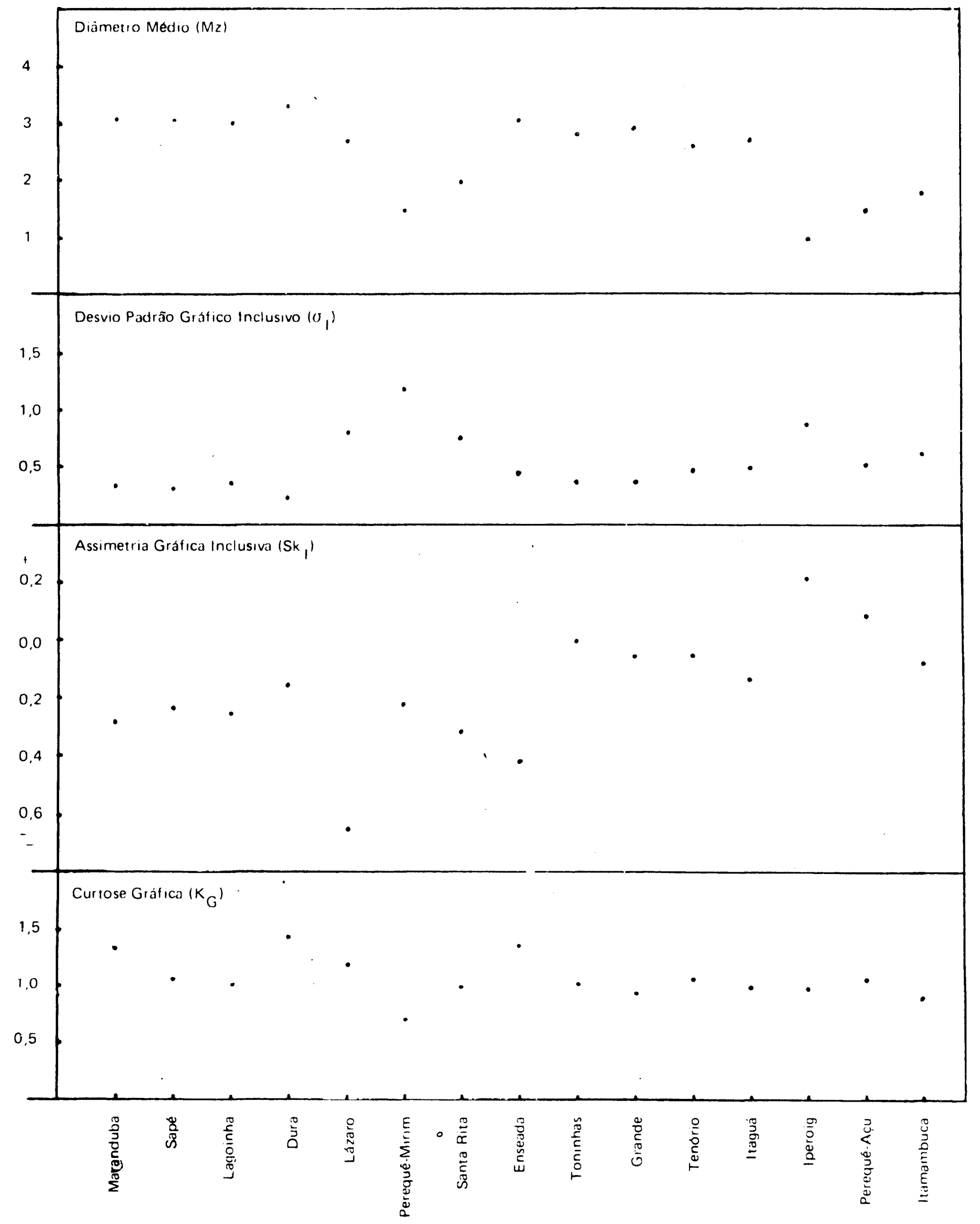

Figura 18 - Relação entre Diâmetro Médio, Desvio Padrão Gráfico Inclusivo, Assimetria Gráfica Inclusiva e Curtose Gráfica, para praias de Ubatuba, SP. 


\section{CONCLUSÖES}

As praias do litoral de Ubatuba são de modo geral, bem selecionadas e constituídas de sedimentos de granulação fina. Constitui exceção a praia de Iperoig, de granulação grossa e mal selecionada.

O material constituinte das praias é melhor selecionado nos sedimentos mais finos.

Ocorre uma nítida e acentuada modificação na assimetria das curvas de distribuição de classes de freqüência, podendo-se distinguir duas regiões: uma, entre as praias de Maranduba e Enseada, com curvas acentuadamente negativas e outra, entre as praias das Toninhas e Itamambuca, com curvas aproximadamente simétricas.

Os resultados obtidos e a situação geográfica das praias sugerem que as areias da Maranduba, Sapé, Lagoinha e Dura provenham do mesmo local de origem. A mesma observação é válida para as praias das Toninhas, Grande, Tenório e Itaguá. Estas conclusões devem ser confirmadas com o estudo mineralógico desses sedimentos.

\section{SUMMARY}

GRANULOMETRIC STUDY OF SAND SAMPLES FROM BEACHES OF THE UBATUBA SHORELINE

This paper deals with the granulometric study of the sand of 15 beaches of the Ubatuba shoreline. The parameters studied were those suggested by Folk and Ward (SUGUIO, 1973): mean size $(\mathrm{Mz})$, inclusive graphic standard deviation $(\sigma \mathrm{I})$, inciusive graphic skewness $\left(\mathrm{Sk}_{\mathrm{I}}\right)$ and graphic kurtosis $\left(\mathrm{K}_{\mathrm{G}}\right)$. The data shows that fine sand is the predominant size class in most of the beaches. The frequency distribution curves show negative skewness and are either meso or leptokurtic.

\section{LITERATURA CITADA}

DOEGLAS, D.J., 1946. Interpretation of the Results of Mechanical Analyses. J. Sed. Petr., 16(1): 19-40.

FREITAS, R.O., 1951 (a). Areais Recentes da Praia Grande, SP. An. Ac. Br. Ciên., 23(2): 163-175.

FREITAS, R.O., 1951 (b). Areias Recentes do Guarujá, SP. An. Ac. Br. Ciên., 23(2): 177-186.

FREITAS, R.O., 1953. Composição e Granulometria da Praia de São Sebastião, SP. Bol. Soc. Br. Geol., 2(1): 29-36.

FRIEDMAN, G.M., 1961. Distinction Between Dune, Beach and River Sands from their Textural Characteristics. J. Sed. Petr., 31(4):514-529.

MARTINS, L.R., 1965. Significance of Skewness and Kurtosis in Environmental Interpretation. J. Sed. Petr., 35: 768-770.

SUGUIO, K., 1973. Introdução à Sedimentologia. Ed. Edgard Blücher Ltda. e Ed. USP, São Paulo, $317 \mathrm{pp}$. 
